Bond University

Research Repository

\title{
Estimation of a term structure model of carbon prices through state spaces methods: a pitch
}

Aspinall, Thomas; Gepp, Adrian; Harris, Geoffrey; Kelly, Simone; Southam, Colette; Vanstone, Bruce $\mathrm{J}$

Published in:

Accounting Research Journal

DOI:

10.1108/ARJ-08-2020-0278

Licence:

CC BY-NC

Link to output in Bond University research repository.

Recommended citation(APA):

Aspinall, T., Gepp, A., Harris, G., Kelly, S., Southam, C., \& Vanstone, B. J. (2021). Estimation of a term structure model of carbon prices through state spaces methods: a pitch. Accounting Research Journal, 34(1), $106-112$. https://doi.org/10.1108/ARJ-08-2020-0278

\footnotetext{
General rights

Copyright and moral rights for the publications made accessible in the public portal are retained by the authors and/or other copyright owners and it is a condition of accessing publications that users recognise and abide by the legal requirements associated with these rights.

For more information, or if you believe that this document breaches copyright, please contact the Bond University research repository coordinator.
} 


\title{
Estimation of a Term Structure Model of Carbon Prices through State Spaces Methods: A Pitch
}

JEL classification: G3, C32

\begin{abstract}
:
Approach:

This paper applies the Pitching Research Template (PRT) developed by Faff $(2015,2019)$ to a research project on estimating the strength of carbon pricing signals under the European Union Emissions Trading Scheme (EU ETS).
\end{abstract}

\section{Purpose:}

The PRT is designed to help pitchers identify the core elements that form the framework of any research project. This letter provides a brief commentary on an application of the PRT to pitch an Environmental Finance research topic, with a personal reflection on the pitch exercise discussed.

\section{Findings:}

The PRT is found to be a valuable tool to refine broad ideas into impactful and novel research contributions. The PRT is recommended for use by all academics regardless of field and particularly $\mathrm{PhD}$ students to structure and communicate their research ideas. The PRT is found to be particularly well suited to pitch replication studies as it effectively summarises both the 'idea' and proposed 'twist' of the replication study.

\section{Originality/Value:}

This letter is a reflection on a research teams experience with applying the PRT to pitch a replication study at the 2020 Accounting and Finance Association of Australia and New Zealand (AFAANZ) event. This event focused on replicable research and was a unique opportunity for research teams to pitch their replication research ideas.

\section{Introduction:}

The Pitching Research Template (PRT) employs a systematic approach that requires pitchers consider core aspects of their research to refine broad ideas into impactful and novel research contributions. This letter describes an application of the Faff $(2015,2019)$ PRT to an Environmental Finance research topic.

We are a team of researchers operating from the Bond Business School, Australia. The first author, a third year doctoral student, was first introduced to the PRT in November 2018 in Professor Faff's Process of Research in Business course at The University of Queensland. Applying the PRT at the start of the first author's $\mathrm{PhD}$ program required him to compile and organize early knowledge and ideas; he has continued to use this valuable and effective resource throughout his studies. This letter provides a reflection upon this research team's experience in using the PRT to collaborate and communicate research ideas and to pitch a replication study at the 2020 AFAANZ Shark Tank event in July 2020. 
This PRT was developed in a nonlinear approach, with feedback from the process shaping both the research idea itself and the proposed academic contribution.

\section{Brief Commentary on using the Pitch Template:}

Table 1 presents a PRT for the Environmental Finance topic of investment under carbon pricing uncertainty under the European Union Emissions Trading Scheme (EU ETS). The key research question is: "How have pricing developments of the EU ETS signalled long-term private investments into emission abatement technology?" This template was developed after a systematic literature review of Real Options applications to emission abatement technologies highlighted both the substantial effect of carbon price stochastic modelling on project value and the lack of research into the application of state space methods to model the EU ETS term structure.

The first author initially used the PRT to pitch this observed gap in the literature to the rest of the team. This highlighted that whilst the motivation and tools were apparent, there was a lack of a clearly defined research 'idea', empirical methodology, and data. The team focused on the key work of Abadie and Chamorro (2008) identified within the literature review, and concluded that a replication study would form the basis of the "idea". Their stochastic model was utilized in several subsequent studies (Heydari et al., 2010; Knoope et al., 2015a, 2015b; Mo and Zhu, 2014). Since the 2008 study, the EU ETS has matured and experienced significant structural changes, motivating the idea of replicating this study on contemporary market data. Expanding the considered stochastic models to include the two-factor shortterm/long-term model described by Schwartz and Smith (2000) gave our work a 'twist'. The biggest challenge when performing replication research is obtaining data utilized within the original study, but our team were fortunate to obtain the study's original dataset from the first author, Professor Luis M. Abadie. This research team had not corresponded with the original authors prior to this study, but initial communication with Professor Luis M. Abadie was responded favourably with the dataset graciously provided.

The PRT was used to pitch the proposed replication study at the 2020 AFAANZ Shark Tank event. Feedback from the "sharks" focused on the "so what?" and "what's new?" aspects of the proposal. They commented that the key papers identified were dated, which highlighted the lack of academic activity within the research area, but also raised concerns that the proposed research was not being performed within the context of current literature. This led to additional citations of more recent studies (Clara and Mayr, 2018) to emphasise the contributions of our work within the context of contemporary literature. This further led to a change in the contemporary dataset used, enhancing the novelty of the research by investigating the effect of the recent large growth in EU ETS prices on carbon pricing signals.

\section{Personal Reflections on the Pitch Exercise:}

Faff (2019) stated that the development of research ideas into a clear and comprehensive research proposal is a challenging and daunting task; this has been our team's experience but using the PRT has helped. The more experienced team members found the initial use of the PRT to be an efficient way to get a new PhD student to articulate their idea. The completed PRT acted as an agenda of sorts that facilitated effective discussion that quickly moved to the key research decisions. The most difficult aspect of the replication study was to demonstrate the "novelty" dimension of the research by answering the question: "so what?". Creating the PRT in a "nonlinear' fashion is this research teams suggested method, because it allows the pitcher to play to the strengths of the research idea, whilst highlighting sections that need further thought and development, with the requirements of each cue forming the basis of an impactful research topic

The Shark Tank event highlighted the challenge this research team experienced identifying relevant key papers: simply because a paper introduces a tool does not mean that it should be a key paper of your study. The PRT requires you to focus beyond the methodology and focus on articles that provide the academic foundation of the relevant literature to which you seek to contribute. While it may be 
appropriate to reference older key papers, you must do so with the knowledge that other papers would not be more appropriate in their stead.

This research team found the process of replicating research to be a rewarding experience as the original study of Abadie and Chamorro (2008) was successfully replicated. Recreating known values provided this research team with modelling experience and verification that the research had been performed correctly. Replicating and subsequently building upon existing research is suggested by this research team when practical, as it allows for direct analysis between original studies and 'twists' in the research of replication studies. Replication studies should be considered when developing models that have been applied within previous studies, the original data is publicly or readily available through private communication, and there is a clear idea for a replication and 'twist' on the original study.

\section{Conclusion:}

This letter describes a research team's personal experience with, and reflections on, the PRT. The PRT of Faff $(2015,2019)$ has grown to be an indispensable tool within the first author's PhD studies to develop, structure, and communicate research ideas. The structure that the PRT provides is a valuable tool for all researchers due to the unstructured nature of academic research, particularly PhD students. The PRT is extremely well suited for pitching replication studies, as it effectively summarises and communicates both the 'idea' and proposed 'twist' the study seeks to perform and allows the pitcher to identify a well specified, valuable replication research idea. Using the PRT to highlight key areas of consideration for a research proposal is crucial to ensuring that contributions to existing literature are relevant, well addressed, and meaningful. 


\begin{tabular}{|c|c|c|c|c|c|}
\hline Pitcher Team Names & & JEL code & $\begin{array}{l}\text { JEL Classification: } \\
\text { C32, C6, E37, D8, G3, } \\
\text { Q48 }\end{array}$ & Date Completed & $31 / 03 / 2020$ \\
\hline (A) Working Title & \multicolumn{5}{|c|}{ The European Union Emissions Trading Scheme: Estimation of the Term Structure of Carbon Prices through State Space Methods. } \\
\hline (B) Basic Research Question & \multicolumn{5}{|c|}{$\begin{array}{l}\text { This research seeks to adopt State Space Methods to estimate the Term Structure of the European Union Emissions Trading Scheme } \\
\text { (EU ETS), investigating the effect of the market structure of Emission Union Allowances on the optimal timing of Carbon Capture } \\
\text { Investments through a Real Options Analysis (ROA). The core research question is identical to that of the original paper that will be } \\
\text { replicated, and the study will consist of a comparative analysis between the originally published and contemporary results. }\end{array}$} \\
\hline (C) Key paper(s) & \multicolumn{5}{|c|}{$\begin{array}{l}\text { Replication Study: Abadie, L. M., \& Chamorro, J. M. (2008). European CO2 prices and carbon capture investments. Energy } \\
\text { Economics, 30(6), 2992-3015. } \\
\text { Schwartz, E. S., \& Smith, J. E. (2000). Short-Term Variations and Long-Term Dynamics in Commodity Prices. Manage. Sci., 46(7), 893- } \\
\text { 911. doi:10.1287/mnsc.46.7.893.12034 } \\
\text { Clara, S. D., \& Mayr, K. (2018). The EU ETS phase IV reform: implications for system functioning and for the carbon price signal. } \\
\text { Retrieved from https://www.oxfordenergy.org/wpcms/wp-content/uploads/2018/09/The-EU-ETS-phase-IV-reform- } \\
\text { implications-for-system-functioning-and-for-the-carbon-price-signal-Insight-38.pdf?v=7516fd43adaa }\end{array}$} \\
\hline (D) Motiv & \multicolumn{5}{|c|}{$\begin{array}{l}\text { The EU ETS is a market-based climate policy that regulates and reduces } \mathrm{CO}_{2} \text { emissions by providing economic signals to polluters to } \\
\text { either reduce emissions or continue to pollute at higher financial costs. This economic signal provides organizations flexibility in } \\
\text { deciding how best to meet emission targets, such as flexibility in the timing of investment into emission abatement technology. One } \\
\text { identified key emissions abatement option for the energy and heavy industry sectors is Carbon Capture technology. Investment into } \\
\text { Carbon capture technology is exposed to high levels of risk: there are low levels of commercial experience in the technology, it } \\
\text { requires a large, irreversible capital investment and features project lifetimes of several decades. The commercial feasibility of } \\
\text { emission abatement technology is largely dependent upon current and expected future price paths of carbon pricing policies. } \\
\text { Accurately modelling carbon prices through appropriate stochastic processes for forecasting purposes is therefore critical in order } \\
\text { to accurately evaluate emission abatement projects. Applying these forecasts in a valuation framework that considers the } \\
\text { technological and market risks of the project and allows the operator to exercise the flexibility of timing investment is also } \\
\text { imperative to maximize the commercial success of emission abatement projects. }\end{array}$} \\
\hline THREE & \multicolumn{5}{|l|}{ Three core aspects of any empirical research project } \\
\hline (E) Idea? & \multicolumn{5}{|c|}{$\begin{array}{l}\text { The work of Abadie and Chamorro (2008) applied State Space Methods and the Kalman Filter to estimate parameters for a } \\
\text { Geometric Brownian Motion (GBM) stochastic process to forecast phase } 2 \text { (2008-2012) EUA spot prices. These estimated values } \\
\text { were subsequently input into a Binomial Lattice ROA model to calculate the critical carbon prices and optimal timing of retrofitting }\end{array}$} \\
\hline
\end{tabular}

This author accepted manuscript is deposited under a Creative Commons Attribution Non-commercial 4.0 International (CC BY-NC) licence. This means that anyone may distribute, adapt, and build upon the work for non-commercial purposes, subject to full attribution. If you wish to use this manuscript for commercial purposes, please contact permissions@emerald.com. 


\begin{tabular}{|c|c|}
\hline & $\begin{array}{l}\text { carbon capture technology to coal-fired power plants. This allowed the study to analyze the commercial feasibility of these projects } \\
\text { given existing market dynamics and expected future price paths. This work was influential in this area of literature due to the State } \\
\text { Space Methods used, with several future works that valued Carbon Capture projects applying these estimated parameter values. } \\
\text { This replication study is proposed to apply State Space methods to estimate parameters for a stochastic process to forecast phase } 4 \\
\text { (2021 - 2030) EUA spot prices. A comparative study of the term structure of the EU ETS, how it has changed over the previous } \\
\text { decade and the effect this has had on the commercial viability of emission abatement projects will then be conducted. } \\
\text { The primary "twist" proposed for this replication study is to apply the Kalman Filter approach to the popular two-factor "Short- } \\
\text { Term/Long-Term Model" proposed by Schwartz and Smith (2000) rather than the GBM stochastic process adopted within the } \\
\text { original paper. The Short-Term/Long-Term model consists of GBM as a nested/restricted model, allowing for the application of a } \\
\text { chi-squared test to prove statistically which model best describes the current term structure of EUA's. This 'twist' will not } \\
\text { undermine the legitimacy of the proposed replication but will instead provide greater empirical evidence into the optimal choice of } \\
\text { stochastic process used for forecasting purposes. }\end{array}$ \\
\hline (F) Data? & $\begin{array}{l}\text { Term Structure of Commodities: } \\
\text { The markets chosen for this replication setting is the EUA Futures contracts listed on the Intercontinental Exchange. The European } \\
\text { Union Emissions Trading Scheme is the world's largest and most mature carbon market. The unit of the ICE EUA Futures contracts is } \\
1,000 \mathrm{tCO}_{2} \mathrm{e} \text {. Phase } 4 \text { futures market data is commercially available through Bloomberg. This dataset will consist of daily prices of } \\
\text { five futures contracts that expire during December of } 2021-2025 \text { (ie. MOZ21, MOZ22, MOZ23, MOZ24, MOZ25). The sampling } \\
\text { period will begin on } 30 / 01 / 2017, \text { the day that phase } 4 \text { futures contracts began being offered, and will apply the most recent data } \\
\text { available at the time of publishing. Currently, this cross-sectional time-series data consists of about 3,770 individual observations. } \\
\text { Furthermore, Phase } 2 \text { futures market data applied during the original study by Abadie and Chamorro (2008) has been graciously } \\
\text { provided by Luis M. Abadie, allowing us to test the short-term/long-term model on both the original and contemporary datasets. } \\
\text { There are no anticipated issues regarding the collection, manipulation / "cleansing" etc. of either the original or contemporary } \\
\text { dataset. } \\
\text { Real Options Analysis: } \\
\text { The financial and technical parameters applied within the original study will be used as inputs into the ROA model of this replication } \\
\text { study. These parameters are purposefully kept constant in order to directly compare the commercial feasibility of carbon capture } \\
\text { projects during phase } 2 \text { and phase } 4 \text { of the EU ETS. }\end{array}$ \\
\hline (G) Tools? & $\begin{array}{l}\text { In the work of Abadie and Chamorro (2008), summary statistics of phase } 2 \text { futures contracts leads to a conclusion that GBM is an } \\
\text { appropriate stochastic process to forecast EUA spot prices. The Kalman Filter generates log-likelihood scores for a given set of } \\
\text { parameters and maximum likelihood estimation is then used to numerically obtain parameter estimates for the GBM process that } \\
\text { best describes the term structure of the observable futures contracts. This parameter estimation methodology is still considered }\end{array}$ \\
\hline
\end{tabular}

This author accepted manuscript is deposited under a Creative Commons Attribution Non-commercial 4.0 International (CC BY-NC) licence. This means that anyone may distribute, adapt, and build upon the work for non-commercial purposes, subject to full attribution. If you wish to use this manuscript for commercial purposes, please contact permissions@emerald.com. 


\begin{tabular}{|c|c|}
\hline & $\begin{array}{l}\text { within literature to be an acceptable method and these techniques will be applied within our replication to an extended two-factor } \\
\text { model. } \\
\text { A difference in ROA approach will be conducted in the replication study. Rather than applying a Binomial Lattice approach, the } \\
\text { Least-Squares Monte Carlo Method (LSM) approach will be applied to value the option to retrofit carbon capture technology. This } \\
\text { alternative tool will be used because the two-factor stochastic process cannot be readily included within a Binomial Lattice } \\
\text { framework. } \\
\text { Both the Kalman Filter parameter estimation and LSM Simulation ROA will be performed using the R statistical computing } \\
\text { programming language, a programming language this research team has significant experience in. }\end{array}$ \\
\hline TWO & Two key questions \\
\hline (H) What's New? & $\begin{array}{l}\text { The work of Abadie and Chamorro (2008) was published as the EU ETS was only just moving out of its pilot phase and sought to } \\
\text { contribute to the increase in academic research into Carbon Capture projects that resulted from the economic signal generated by } \\
\text { the development of the EU ETS. The novelty of this research was to present parameter estimates to model long-term price } \\
\text { forecasts of the EU ETS and ultimately conclude through a ROA whether the development of the EU ETS would result in investment } \\
\text { into Carbon Capture Projects. The EU ETS has experienced several key structural changes since the publication of this work and } \\
\text { continued to mature as a carbon market and is preparing to enter its fourth phase. This proposed replication will amplify this } \\
\text { original study by modelling the term structure of EUA's as a two-factor model in order to prove statistically which model best } \\
\text { describes the characteristics of the EU carbon market. This replication study will also provide insight into how the structural } \\
\text { changes and maturing over the EU ETS over the last approximate decade has affected pricing signals for investment into Emission } \\
\text { Abatement technologies, including Carbon Capture projects. }\end{array}$ \\
\hline (I) So What? & $\begin{array}{l}\text { The impact on current and expected future EUA spot prices on the commercial viability of emission abatement projects is of critical } \\
\text { interest to several parties. Emission abatement projects are capitally intensive and highly risky. Polluters that operate in highly } \\
\text { competitive markets, such as energy production, therefore do not want to lose this competitive edge by over or under investing in } \\
\text { emission abatement technology. Accurate valuation of these projects under relevant market and technological uncertainty is thus } \\
\text { key to the success of these projects. European policy makers also receive important price setting information regarding whether the } \\
\text { economic signals provided by the ETS are strong enough to meet long-term climate policy goals through private polluters triggering } \\
\text { investment into emission abatement projects. Finally, it provides key financial information into other academic research into the } \\
\text { design and operation of these emission abatement projects allowing them to determine how close these technologies undergoing } \\
\text { research are to becoming commercially viable. }\end{array}$ \\
\hline ONE & One bottom line \\
\hline (J) Contribution? & $\begin{array}{l}\text { This replication study will primarily contribute to existing literature by providing contemporary parameter values for forecasting } \\
\text { EUA spot prices for valuation purposes, with the particular stochastic process proven statistically to provide the greatest fit to the } \\
\text { EU ETS carbon market. The replication will also contribute by providing the valuation model and Kalman Filter parameter estimation }\end{array}$ \\
\hline
\end{tabular}

This author accepted manuscript is deposited under a Creative Commons Attribution Non-commercial 4.0 International (CC BY-NC) licence. This means that anyone may distribute, adapt, and build upon the work for non-commercial purposes, subject to full attribution. If you wish to use this manuscript for commercial purposes, please contact permissions@emerald.com. 


\begin{tabular}{|l|l|}
\hline & $\begin{array}{l}\text { process as R scripts available for download online, allowing others to both understand the process undertaken and apply these } \\
\text { models to other case studies. A final contribution will be, given that the Short-Term/Long-Term model is proven statistically to be } \\
\text { the most appropriate stochastic process, the research will prove that the most appropriate ROA model to value Carbon Capture } \\
\text { projects is the LSM simulation method due to the exotic stochastic process that must be incorporated within the valuation } \\
\text { framework. }\end{array}$ \\
\hline (K) Other Considerations & No other relevant considerations for this project can be made at this time. \\
\hline
\end{tabular}




\section{References}

Abadie, L. M., and J. M. Chamorro, 2008, European CO2 prices and carbon capture investments. Energy Economics, 30, 2992-3015.

Clara, S. D., and K. Mayr. 2018. The EU ETS phase IV reform: implications for system functioning and for the carbon price signal. Available at: https://www.oxfordenergy.org/wpcms/wpcontent/uploads/2018/09/The-EU-ETS-phase-IV-reform-implications-for-system-functioningand-for-the-carbon-price-signal-Insight-38.pdf?v=7516fd43adaa

Faff, R. W., 2015, A simple template for pitching research. Accounting \& Finance, 55, 311-336.

Faff, R. W., 2019, Pitching research®. Available at SSRN 2462059.

Heydari, S., N. Ovenden, and A. Siddiqui, 2010, Real options analysis of investment in carbon capture and sequestration technology. Computational Management Science, 9, 109-138.

Knoope, M. M. J., A. Ramírez, and A. P. C. Faaij, 2015a, The influence of uncertainty in the development of a CO2 infrastructure network. Applied Energy, 158, 332-347.

Knoope, M. M. J., A. Ramírez, and A. P. C. Faaij, 2015b, Investing in CO2 transport infrastructure under uncertainty: A comparison between ships and pipelines. International Journal of Greenhouse Gas Control, 41, 174-193.

Mo, J.-L., and L. Zhu, 2014, Using floor price mechanisms to promote carbon capture and storage (CCS) investment and CO2 abatement. Energy \& Environment, 25, 687-707.

Schwartz, E. S., and J. E. Smith, 2000, Short-Term Variations and Long-Term Dynamics in Commodity Prices. Manage. Sci., 46, 893-911. 